\title{
Humedales, riesgo de desastres y cambio climático en la Región Metropolitana de Buenos Aires. Entre imaginarios geográficos, conflictos ambientales y políticas públicas
}

Diego Ríos

Universidad de Buenos Aires. Facultad de Filosofía y Letras. Departamento de Geografía/ Instituto de Geografía "Romualdo Ardissone". Buenos Aires, Argentina. CONICET. Buenos Aires, Argentina.

\author{
Sergio Caruso \\ Universidad de Buenos Aires. Facultad de Filosofía y Letras. Departamento de \\ Geografía/ Instituto de Geografía "Romualdo Ardissone". Buenos Aires, Argentina. \\ CONICET. Buenos Aires, Argentina.
}

Recibido: 10 de junio de 2021. Aceptado: 22 de julio de 2021.

\begin{abstract}
Resumen
La mayor frecuencia e intensidad de eventos hidrometeorológicos extremos, atribuidos al cambio climático y a la proliferación de formas inadecuadas de urbanización en áreas bajas de la Región Metropolitana de Buenos Aires, han amplificado el poder destructivo de las inundaciones. Esto colocó en la agenda pública las formas controversiales en las que esas tierras y los humedales se incorporan a la trama urbana. En este contexto, basados en los postulados del ambientalismo y de la Reducción de Riesgo de Desastres ante el cambio climático derivada del Marco de Sendai, los humedales han cobrado una nueva notoriedad. Consideramos que ese reposicionamiento se debe a una serie de procesos interrelacionados: 1) cambios en los imaginarios geográficos, en los que la trama de sentido pone en valor a los bienes y servicios brindados por estos ecosistemas; 2) la emergencia de conflictos ambientales gestados por la contraposición de intereses, visiones y acciones entre los distintos actores sociales que participan en su urbanización y en el tipo de uso otorgado a esas tierras, y 3) la elaboración de políticas públicas tendientes tanto a la conservación de los humedales como al desarrollo de medidas de mitigación y adaptación al cambio climático bajo el paradigma de la modernización ecológica. Desde una mirada crítica, este trabajo busca describir y analizar los tres procesos antes señalados, así como plantear posibles líneas de investigación sobre el desarrollo de soluciones tecnocráticas basadas en la naturaleza que favorecen nuevas formas de mercantilización; las implicancias de las incipientes políticas en la materia, y el papel que tienen los grupos de más bajos recursos ante este escenario.
\end{abstract}




\title{
Wetlands, Disaster Risk and Climate Change in the Metropolitan Region of Buenos Aires. Between Geographical Imaginaries, Environmental Conflicts and Public Policies
}

\begin{abstract}
The greater frequency and intensity of extreme hydrometeorological events, attributed to climate change and the proliferation of inappropriate forms of urbanization in lowlying areas of the Metropolitan Region of Buenos Aires, have amplified the destructive power of floods. This placed on the public agenda the controversial ways in which these lands and wetlands are incorporated into the urban fabric. Based on the postulates of environmentalism and Disaster Risk Reduction in the face of climate change derived from the Sendai Framework, wetlands have gained a new notoriety. We consider that this repositioning is due to a series of interrelated processes: 1) changes in geographic imaginaries, in which the network of meaning gives value to goods and services provided by these ecosystems; 2) the emergence of environmental conflicts derived by the opposition of interests, visions and actions between the different social actors that participate in its urbanization and in the type of use granted to these lands, and 3) the elaboration of public policies tending both to the conservation of wetlands and the development of mitigation and adaptation measures to climate change under the paradigm of ecological modernization. From a critical point of view, this work seeks to describe and analyze the three processes mentioned above, as well as to propose possible research lines regarding the development of technocratic solutions based on nature that favor new forms of commodification; the implications of incipient policies in this matter and the role that the lowest-income groups play in this scenario.
\end{abstract}

KEYWORDS: WETLANDS. DISASTER RISK. GEOGRAPHICAL IMAGINARIES. ENVIRONMENTAL CONFLICTS. PUBLIC POLICIES.

PALAVRAS-CHAVE: HUMIDAIS. RISCO DE DESASTRES. IMAGINÁRIOS GEOGRÁFICOS. CONFLITOS AMBIENTAIS. POLÍTICAS PÚBLICAS.

\section{Introducción}

En las últimas décadas, y en especial tras la difusión de los preceptos de la Convención Ramsar, los humedales han ido ganando espacio y relevancia en las agendas públicas globales ante las consecuencias ambientales adversas generadas por el avance del capital minero, agroindustrial e inmobiliario, entre otros. Ello ha implicado un acelerado proceso de deterioro y depredación de las bases físicas y la eliminación de los servicios que estos sitios brindan a la sociedad.

En varias oportunidades, esos ambientes se convirtieron en suelos asequibles para la expansión urbana protagonizada por los extremos socioeconómicos. Sociedades profundamente desiguales e injustas, como las latinoamericanas, reproducen paisajes urbanos sumamente disímiles e incluso muchas veces adyacentes, tornándose más notables esas características diferenciales en los ámbitos suburbanos. Por un lado, se hallan barrios modernos, embellecidos, forestados, conectados a redes tecnológicas, con oferta de toda clase de bienes y servicios, habitados por los grupos más acomodados. La incorporación urbana protagonizada por estos últimos ha implicado mayormente una transformación radical de los humedales mediante la implementación de 
técnicas de polderizaciones, refulados hidráulicos y otros tipos de movimientos de suelos, conllevando una sustitución de los rasgos singulares de esos paisajes por otros de índole escenográfica. Mientras que, por otro lado, abundan las barriadas periféricas de viviendas precarias autoconstruidas, carentes de la mayor parte de bienes y servicios, en donde habitan los grupos más marginalizados, quienes han avanzado sobre los humedales más degradados y contaminados. En esta configuración de la trama urbana, los desarrolladores inmobiliarios inescrupulosos y los Estados complacientes y facilitadores -bajo los principios rectores del urbanismo neoliberal- se convirtieron en actores sociales protagónicos de la producción (por acción u omisión) de esos paisajes desiguales, beneficiando a las minorías más poderosas y perjudicando a las mayorías más relegadas en la distribución de bienes y servicios de las condiciones ecosistémicas (Collins, 2010; González y Ríos, 2015).

Entretanto, el cambio climático (CC) ha activado severas modificaciones en términos de frecuencia, intensidad, duración y alcance espacial de los eventos hidrometeorológicos extremos. ${ }^{1}$ Sus capacidades de afectación sobre sociedades, ambientes y territorios son cada vez más inocultables, tal como lo demuestra el incremento de desastres (y de sus consecuencias en términos de víctimas fatales y bienes afectados) acontecidos durante las últimas décadas, en diferentes lugares del mundo. En el caso de los ámbitos urbanos, los eventos extremos del agua encuentran mayor severidad. Situación signada por ser las ciudades donde reside la mayoría de la población mundial, además de concentrar buena parte del desarrollo económico, científico-técnico, de innovación y cultural, y tener asiento en ellas las instituciones político-administrativas y jurídicas más importantes a escala global.

Ante este contexto, las condiciones de los ecosistemas nativos, tradicionalmente desconsiderados y dispendiados en las urbes, como por ejemplo costas marítimas o bosques, comienzan a ser valoradas en virtud de los servicios ambientales que pueden brindarles a los espacios citadinos para hacer frente al CC. En particular, se destacan los humedales, cuyos servicios ambientales en materia de regulación favorecen (a) la mitigación del calentamiento global, al operar como eficientes sumideros de gases de efecto invernadero (tal es el caso del dióxido de carbono que es metabolizado por la fotosíntesis de la vida vegetal), y (b) la adaptación ante los impactos de los eventos hidrometeorológicos extremos, puesto que sus propias condiciones físicas amortiguan el potencial destructivo de las tormentas e inundaciones cada vez más violentas.

La estimación de esos servicios también radica en que pueden coadyuvar a las medidas de reducción de riesgo de desastre (RRD) ${ }^{2}$ ante el CC. Se trata de una temática que, junto a la gestión de riesgos de desastre, ha registrado un nuevo impulso en sus estudios.

1 De acuerdo con Barros y Camilloni (2016), los eventos meteorológicos extremos se caracterizan por ser episodios cuya duración es menor a una semana. Cuando superan dicho rango temporal, extendiéndose durante meses o incluso años, se trata de eventos climáticos extremos. Cabe decir que el $90 \%$ de los desastres "naturales" a escala mundial tienen origen en los excesos o carencias del agua.

2 El Marco de Acción de Hyogo-Japón (2005-2015) consistió en el instrumento institucional más importante para la implementación de la RRD, adoptado por los estados miembros de las Naciones Unidas. El Marco de Sendai-Japón (2015-2030), adoptado por ese mismo organismo internacional de cooperación, es considerado el instrumento institucional sucesor del anterior. 
Los organismos internacionales de cooperación especializados (IPCC, ${ }^{3}$ UNISDR, ${ }^{4}$ etc.) recomiendan una serie de propuestas que abordan el tratamiento de las condiciones climáticas extremas (en términos de amenazas), las mejoras en el desarrollo socioeconómico de las sociedades (en términos de vulnerabilidades), las estrategias de mitigación y adaptación en los respectivos territorios (en términos de exposiciones), así como el entrelazamiento entre estas tres dimensiones, colocando a la RRD ante el CC como eje transversal y prioritario (Ríos y Natenzon, 2015).

En este punto, debe destacarse que la generación de espacios de riesgo de desastres en los ámbitos urbanos no es algo nuevo, menos aún en el contexto latinoamericano. A pesar de ello, este proceso se ha potenciado de una manera acelerada desde finales del siglo pasado producto de las modificaciones en las dinámicas climáticas, así como también de la velocidad y expansión de la urbanización capitalista neoliberal, mucho más intensa que en otros momentos históricos. Por el lado de las amenazas y exposiciones, ello se explica debido a una mayor frecuencia e intensidad de fenómenos hidrometeorológicos extremos activados por el CC. El poder destructivo de esos fenómenos está siendo amplificado debido a las transformaciones impropias infringidas a los ecosistemas urbanizados, debilitando (o hasta, incluso, desapareciendo) los servicios de regulación que estos últimos brindan ante los eventos peligrosos. Por el lado de las vulnerabilidades y exposiciones, la profundización de las desigualdades socioeconómicas derivadas de la implementación de políticas neoliberales ortodoxas (en materia económica, social, de salud, etc.) marginaliza y vulnerabiliza a amplias franjas de las sociedades urbanas, las que se ven empujadas a habitar de manera precaria zonas degradadas ambientalmente en las que suelen acontecer fenómenos extremos (De Souza Porto, 2007). En consecuencia, las anteriores dimensiones interrelacionadas son las que producen los espacios de riesgo de desastres, alcanzando últimamente niveles de desigualdad y de injusticia socioambiental que se han convertido en inaceptables (Calderón, 2001; Ríos y Natenzon, 2015). La aseveración de Elizabeth Mansilla (2000), realizada a comienzo de este nuevo siglo, adquiere cada vez mayor trascendencia: las ciudades se han tornado en el espacio de riesgo por excelencia, razón por la cual esta temática se ha posicionado en el centro de las agendas urbano-ambientales de todo el mundo.

Las implicancias sociales y ambientales que supuso la incorporación de los humedales a las ciudades bajo la lógica rectora del urbanismo neoliberal, sumadas a las consecuencias adversas atribuidas al CC, condujeron a que las comunidades locales reclamaran políticas públicas de conservación de esos ambientes mediante áreas protegidas (AP) u otros mecanismos eficaces. Estas demandas no sólo atañen a cuestiones relativas a la biodiversidad, sino también a aquellas relacionadas con los medios de vida y la identidad de los grupos que interactúan y se hallan vinculados con las fluctuaciones de esas "tierras de agua”. Todo lo cual explica que estos sitios se hayan tornado en ámbitos propicios para la disputa entre actores sumamente distantes en términos socioeconómicos y en las relaciones de fuerza, así como también en sus valoraciones respecto de las formas de aprovechamiento y uso de los humedales. Frecuentemente, las tensiones mencionadas han derivado en situaciones de alta conflictividad ambiental.

3 IPCC por sus siglas en inglés (Intergovernmental Panel on Climate Change).

4 La Oficina de las Naciones Unidas para la Reducción del Riesgo de Desastres. 
Humedales, riesgo de desastres y cambio climático...

Diego Ríos, Sergio Caruso

Un compendio de procesos simultáneos está poniendo de relieve los múltiples imaginarios, controversias y regulaciones que tienen como objeto central a los humedales urbanos durante los últimos tiempos. Entre ellos sobresalen: la difusión del conocimiento científico-técnico acerca de los bienes y servicios ecosistémicos que brindan los humedales; la mercantilización de recursos paisajísticos asociados con el agua por parte del mercado inmobiliario; el incremento en cantidad y densidad poblacional de asentamientos precarios en áreas inundables urbanas; las políticas públicas de conservación a través de las AP o de puesta en valor a partir de su conversión en parques públicos costeros, y las resistencias por parte de organizaciones de base y ambientalistas.

Entendemos que este reposicionamiento de los humedales en los ámbitos urbanos, considerados hasta hace poco tiempo atrás como "los patitos feos" de los paisajes citadinos, se fundamenta en la activación de una serie de procesos interrelacionados: 1) cambios en la trama de sentidos de los imaginarios geográficos sobre las áreas inundables urbanas influenciada, por un lado, por los discursos del conocimiento científico-técnico con el que se ponen en valor los bienes y servicios brindados por estos ecosistemas y, por el otro, por los discursos e imágenes publicitarias de los desarrolladores de urbanizaciones cerradas (UC) ${ }^{5}$ que buscan transformar el agua y demás condiciones de esos ecosistemas en recursos paisajísticos estetizados; 2) conflictos ambientales derivados de las consecuencias adversas generadas por las técnicas inapropiadas de urbanización (con especial repercusión en la alteración de las inundaciones), en los que participan otros actores sociales en la defensa, uso y restauración de esos ecosistemas, y quienes ponderan otras formas de valoración no económicas, y 3) elaboración de políticas públicas tendientes a la conservación de los humedales, así como al aprovechamiento de sus servicios en función de las medidas de mitigación y adaptación ante el CC (en las que también se incluyen propuestas artificiales) bajo el paradigma de la modernización ecológica. ${ }^{6}$

Desde una mirada crítica, este trabajo busca contribuir a la comprensión de las relaciones entre sociedad, ciudades, humedales y políticas de RRD ante el CC, a través de una descripción y análisis que permita un primer acercamiento de los tres procesos indicados (y sus interrelaciones), tomando como referentes empíricos algunos casos de la Región Metropolitana de Buenos Aires (RMBA). ${ }^{7}$ Para alcanzar este objetivo, la metodología empleada ha sido de tipo cualitativa, sustentada en fuentes secundarias (bibliografía, documentos, sitios web) y trabajo en campo.

5 Se trata de aquellos asentamientos privados construidos por fuera de la red pública de la ciudad; que se hallan separados físicamente por una barrera material y que generan de forma privada los servicios urbanos, educativos, de recreación, etc., hacia el interior de esos espacios (Ríos y Pírez, 2008).

6 La teoría de la modernización ecológica surge en Alemania durante la década de 1980 y aborda el entendimiento de la transformación ambiental de la sociedad, analizando las modificaciones detectadas en los planos político, cultural y económico. Aquí se le atribuye un rol central a la ciencia y a la tecnología como elementos clave para la reorganización institucional de la sociedad con el fin de afrontar la crisis ecológica. Se considera que la economización de la ecología y la valorización de los recursos naturales conllevarán cambios en los procesos de producción y de consumo de la sociedad. Sin embargo, como advierte Oltra (2005), esta corriente de carácter tecnocrático, al reducir el abordaje de los problemas ambientales a meras cuestiones de índole técnica, soslaya las causas políticas y económicas de fondo.

7 El RMBA comprende una regionalización operativa y funcional que abarca a la Ciudad Autónoma de Buenos Aires y 40 partidos de la provincia de Buenos Aires. 


\section{Buenos Aires y sus humedales: transformaciones históricas y recientes}

A pesar de que la segunda fundación de la ciudad de Buenos Aires se realizó sobre una meseta elevada, fuera del alcance de los eventos extremos de las aguas del Plata y del Riachuelo (sudestadas ${ }^{8}$ y crecientes), ese asentamiento se fue expandiendo predominantemente por tierras altas, pero también fue anexando cursos y cuerpos de aguas y tierras inundables adyacentes, reencontrándose de alguna manera con aquellos peligros que se quisieron evitar. Esa incorporación urbana nos muestra una nutrida y controversial historia, en tanto que esas condiciones de "tierras de agua" fueron consideradas un obstáculo, un límite a sortear para la expansión "interminable" de la cuadrícula urbana: el damero formado por calles y manzanas (Williams, 2017). Con el pasar de los siglos, la "gran aldea" siguió extendiéndose físicamente sobre las tierras altas y bajas formando el aglomerado más importante de la Argentina que, en términos funcionales, integra a otros asentamientos urbanos y áreas de influencia que conforman la RMBA, con más de quince millones de habitantes.

La Ciudad de Buenos Aires y su región metropolitana están rodeadas de aguas y de áreas inundables muchas de ellas valoradas como ambientes de humedales, pudiéndose establecer -siguiendo una adaptación del criterio hidrogeomorfológico adoptado por Pereyra (2002) - una tipología de cuatro categorías: a) el Delta del río Paraná (1 $1^{\mathrm{a}}$ y $2^{\mathrm{a}}$ sección de islas); b) los bajos ribereños del Río de la Plata formado por planicies de marea antigua y cordones litorales; c) las planicies aluviales y terrazas fluviales de ríos y arroyos que atraviesan la región (Luján, Reconquista y Matanza-Riachuelo, entre las principales cuencas metropolitanas), todas ellas tributarias de los ríos Paraná y de la Plata, y d) las lagunas pampeanas cercanas pertenecientes a la cuenca del SaladoVallimanca (como el caso de la Laguna de San Vicente); todos ellos conectados a las aguas subterráneas de los acuíferos Pampeano y Puelche (véase Figura 1).

La sociedad metropolitana fue acondicionando esos diferentes tipos de humedales para usos urbanos específicos, en función de las condiciones de los sitios y su posición (en términos del aprovechamiento de sus bienes y servicios), de las políticas públicas urbanas llevadas adelante, de los imaginarios geográficos construidos sobre esas áreas para cada contexto histórico, de su valorización en el mercado de tierras, etc. Ese acondicionamiento implicó la transformación de la condición amorfa propia de los humedales, cuyas tierras y aguas se hallaban profundamente entrelazadas. Mediante la utilización de distintas técnicas hidráulicas se trató de lograr formas definidas con límites precisos que escindieran a sus elementos (Silvestri, 2003). Los rellenos de áreas bajas o los utilizados para ganarle tierras a las aguas someras del Plata, las canalizaciones, entubamientos, represamientos de cursos de agua y los cegamientos de cuerpos de agua, fueron algunas de las obras hidráulicas de las que más se valieron los equipos técnicos para alcanzar esas finalidades, bajo los paradigmas ingenieriles predominantes del momento (higienista, racionalista, etc.) (Ríos, 2010; González, 2018).

8 Mareas meteorológicas que impiden el normal escurrimiento de las aguas del Plata y de sus tributarios, ocasionando inundaciones sobre las costas bonaerenses e islas del Delta del Paraná según la constancia y velocidad de los vientos provenientes del cuadrante sudeste, los cuales pueden estar acompañados de lluvias débiles a moderadas. 


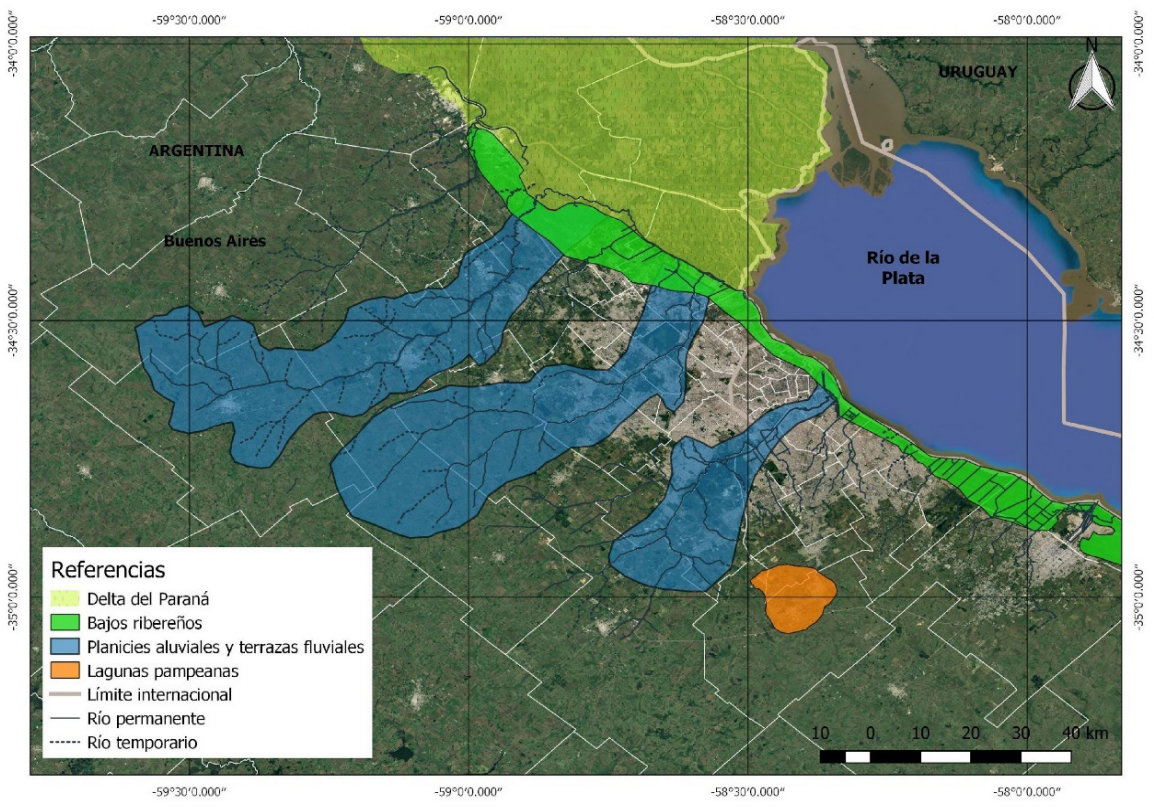

Figura 1. Tipología esquemática de los humedales de la RMBA. Fuente: elaboración propia a partir de Google Earth e información geoespacial disponible en el Instituto Geográfico Nacional. Diseño Lic. Mariana Lipori.

Entre los usos urbanos (no excluyentes entre sí) otorgados a las aguas y tierras inundables adyacentes -referidas a los distintos tipos de humedales de la RMBA antes señalados-, podemos resaltar algunos de los más representativos: portuarios, industriales, infraestructuras de transporte (vial, ferroviaria, aeroportuaria), parques públicos y áreas recreativas, sistemas de desagües pluviales, plantas potabilizadoras y de tratamientos de efluentes cloacales, residenciales (protagonizado tanto por las poblaciones más marginalizadas, así como por los grupos dominantes), entre otros.

Salvo algunas pocas excepciones, los humedales de la RMBA fueron escasamente valorados por los grupos más acomodados, como así también por la propia dinámica del mercado legal de tierras en cada momento histórico. ${ }^{9}$ Varios de los destinos urbanos antes señalados influyeron en la construcción de sentido sobre los humedales, predominando valoraciones negativas en las que se entrelazaron aspectos locacionales, sociales y ambientales: anegamientos e inundaciones consideradas peligrosas en determinadas zonas y cuencas; propagación de pestes y enfermedades (como las señaladas por los discursos y prácticas lideradas por el higienismo a fines del siglo XIX); localización predominante de los grupos marginales (de los barrios del tambor a las villas miserias); radicación de actividades industriales contaminantes (saladeros, frigoríficos, curtiembres, petroquímicas); depósitos de residuos sólidos urbanos (desde el barrio de las ranas o de las latas a los rellenos sanitarios de la Coordinación Ecológica Área Metropolitana Sociedad del Estado (CEAMSE)); utilización de sus tierras desoladas para tareas clandestinas represivas y de violación de derechos humanos (como el Centro Clandestino de Detención "La

9 Tal es el caso de Las Conchas/Tigre que, por su cercanía al singular paisaje de las islas del Delta del Paraná, fue convertido por las élites porteñas en una opulenta villa de veraneo y recreación (remo, baños, etc.) entre las décadas de 1860 y 1930 o el caso de algunas zonas inundables saneadas de Palermo sobre las que Charles Thays propuso un barrio parque a comienzos del siglo XX: Palermo Chico. 
Diego Ríos, Sergio Caruso

205” en Esteban Echeverría); sitios de descarte de actividades delictivas (como el caso de la Reserva Santa Catalina donde ya se hallaron varios cadáveres), entre otras tantas múltiples valoraciones.

Esas connotaciones negativas no se redujeron solamente a las condiciones topográficas inferiores y a los usos urbanos degradantes a los que fueron destinados los humedales en cuanto paisajes escasamente valorados, sino también refieren a las condiciones socioeconómicas, culturales, ambientales y de legitimidad de aquellos que los ocuparon y que en ellos encontraron su sustento. La manera en que el habla ha denominado a lo largo del tiempo a las áreas inundables y a sus habitantes revela, precisamente, cómo ha operado una amalgama físico-sociolingüística sobre este aspecto. En el caso de la Ciudad de Buenos Aires y sus alrededores, son notables los términos que aluden a esa operación del habla: orillas/ "orilleros"; arrabales/ "arrabaleros"; áreas marginales/ "grupos marginales" o "en los márgenes de la ley”; tierras bajas/ "clases bajas", entre otras.

A partir de la década de 1970, muchas de las tierras húmedas pasaron a convertirse en territorios en disputa entre los extremos socioeconómicos. Los grupos más marginalizados y vulnerabilizados - que ya contaban con una extensa historia de urbanización de esos ámbitos- incrementaron su presencia en esas tierras al no quedarles más opciones para formar parte de la ciudad. Las consecuencias de las políticas económicas, sociales, habitacionales, etc. de corte neoliberal profundizaron las carencias de esos grupos, aumentando la cantidad y la densidad poblacional de los asentamientos informales en áreas inundables (Cravino et al., 2008).

La novedad fue que desde ese entonces los grupos más beneficiados comenzaron a adquirir viviendas en UC (clubes de campo y barrios cerrados) ofrecidas por el mercado inmobiliario bajo un seductor discurso ecológico, cuya localización predominante estuvo en función de la disponibilidad de grandes cantidades de tierras económicas en humedales cercanos a las redes de autopistas metropolitanas. La expansión de este fenómeno ocurrió principalmente en los municipios de la llamada Zona Norte de la metrópolis, pero luego se replicó en otras áreas inundables de la región, llegando, incluso, a ser emulada en otras ciudades del país con esas mismas condiciones ambientales. ${ }^{10}$

\section{Cambios en la trama de sentidos de los imaginarios geográficos sobre las áreas inundables}

Las transformaciones que las sociedades llevan adelante respecto de las áreas inundables -como pueden ser las distintas formas de su incorporación urbana- no se reducen sólo a su mera apariencia material, sino que están articuladas con una producción de sentidos sustentada en un complejo entramado de figuraciones (imágenes fotográficas, cartográficas, planos urbanísticos, etc.) y discursos que justifican, legitiman y retroalimentan las acciones que trasmutan sus caracteres tangibles. Ese entramado de figuraciones y discursos sobre determinados accidentes topográficos o áreas (tales como montañas, selvas, desiertos, suburbios exclusivos, etc.), construidos mayormente por los grupos dominantes, configuran imaginarios geográficos que tienen claras implicancias 
Diego Ríos, Sergio Caruso

en las intervenciones materiales, al tiempo que estas últimas repercuten en la gestación y readaptación de los imaginarios geográficos (Hiernaux y Lindón, 2007).

La prolífera historia de valoraciones negativas que integran los imaginarios geográficos de las áreas inundables de la RMBA antes señalada alcanza un giro hacia finales del siglo $\mathrm{XX}$. Los avances en el conocimiento científico provenientes del campo de la ecología y la biología, desarrollados a nivel mundial (con notable liderazgo de los Estados Unidos) y luego a nivel nacional y metropolitano, ocuparon un papel central en esa reinversión de sentidos respecto de las valoraciones de esas áreas de condición "anfibia".

En su libro Discovering the Unknown Landscape. A History of American's Wetlands, Ann Vileisis (1999) sostiene que los humedales de los Estados Unidos forman parte de los paisajes más desconocidos, bastardeados y dañados. Si bien el destrato otorgado a esos ambientes se inició con la colonización británica (valoración totalmente opuesta de la que mantenían los pueblos originarios) éste se tornó más visible públicamente hacia fines de la década de 1950. Olga Owen Huckins escribió en 1957 una carta a un diario horrorizada por el envenenamiento de decenas de aves debido a la aspersión de $\mathrm{DDT}^{11}$ en humedales y su amiga, Rachel Carson, convirtió ese problema en su popular libro Silent Spring (1962). Esa experiencia sirvió para inspirar a innumerables estadounidenses a exigir mayor atención sobre los temas ambientales, constituyéndose en un hito fundante del ambientalismo y del desarrollo de ONG ambientalistas, con repercusiones tanto en los Estados Unidos como en el resto del mundo.

Una década después, el ritmo alarmante de disminución de aves acuáticas y de las áreas húmedas que constituían sus hábitats motivó el desarrollo de reuniones entre Estados, ONG y científicos especializados para detener ese proceso. Fruto de las negociaciones en esas reuniones se creó uno de los tratados ambientales intergubernamentales de escala global más antiguos: la Convención Relativa a los Humedales de Importancia Internacional Especialmente como Hábitat de Aves Acuáticas, que fue firmado en la localidad iraní de Ramsar en 1971 y entró en vigencia en 1975, por lo que se la conoce como la Convención Ramsar (Kandus y Minotti, 2018). En esa convención se alertó sobre los efectos negativos de la alteración, invasión o pérdida de humedales y se estableció una serie de parámetros para su conservación y manejo racional, haciendo conocer los distintos bienes y servicios que estos ecosistemas brindaban a la humanidad y al mantenimiento de la vida en general en la Tierra. ${ }^{12}$

Estados Unidos fue líder en las primeras investigaciones sobre humedales. Howard T. Odum, pionero en la ecología de los ecosistemas, fundó en la Universidad de Florida el primer Centro de Humedales del Mundo en 1973. Luego, ya en la década de los ochenta, el libro Wetlands de William J. Mitsch y James G. Gosselink ([1986] 1993) ${ }^{13}$ se posicionó como una obra de gran profundidad que abarcaba diferentes aspectos vinculados a este singular tipo de ecosistemas, convirtiéndose en una referencia obligatoria de gran parte de los investigadores que han avanzado en el estudio de este campo desde el enfoque de la ecología.

11 De esta manera se denomina usualmente al insecticida diclorodifeniltricloroetano, el cual fue aplicado en el control de plagas para todo tipo de cultivos desde mediados del siglo XX.

12 Página web oficial: https://www.ramsar.org/es

13 Actualmente esta publicación se encuentra por su quinta edición. 
Diego Ríos, Sergio Caruso

Este conjunto de investigaciones e instituciones puso de relieve que el funcionamiento, la morfología, el tipo de suelos y la vida de esos ecosistemas están definidos por el agua (sean dulces, salobres o saladas) tanto en su estado permanente como temporario. Se trata de sistemas donde el régimen hidrológico es el principal condicionante de las funciones y la estructura ecológica (Kalesnik y Quintana, 2006). La hibridez de estos ecosistemas (ni terrestres, ni acuáticos) se manifiesta bajo formas heterogéneas, tales como: bañados, deltas, lagunas salobres de altura, turberas, manglares, sistemas coralinos, etc. Los avances de la ecología de los ecosistemas posibilitaron la profundización del conocimiento acerca de los servicios de regulación hidrológica (regulación de inundaciones, recargas de acuíferos, etc.), de regulación bioquímica (transformación y degradación de contaminantes, etc.) y ecológicos (producción primaria y secundaria, provisión de hábitat, etc.) que ofrecen los humedales (Benzaquén et al., 2017).

Más adelante, la publicación Evaluación de los Ecosistemas del Milenio (2005) instaló la cuestión de los servicios ambientales como una temática de la agenda global. Su objetivo fue ofrecer a los tomadores de decisiones en los gobiernos de los países y en las convenciones internacionales una síntesis de la información disponible respecto de los vínculos entre los ecosistemas y el bienestar humano.

En Argentina, especialmente en la RMBA, la ecóloga Inés Malvárez de la Facultad de Ciencias Exactas y Naturales de la Universidad de Buenos Aires (FCEyN, UBA) fue una de las pioneras en el estudio de humedales a partir de la década de 1990, alcanzando un papel destacado en la formación de profesionales. De ese seno surgieron dos de los grupos de investigación que más han avanzado en ese campo, cuyos estudios se han centrado principalmente (aunque sin ser excluyentes) en el Delta del Paraná: el Grupo de Investigación en Ecología de Humedales (en esa misma facultad y creado por ella) cuyos principales referentes son Roberto Bó, Nora Madanes y Fabio Kalesnik, entre otros; y los investigadores que integran el Instituto de Investigación e Ingeniería Ambiental de la Universidad Nacional de San Martín (3iA, UNSAM), entre los que se destacan Rubén Quintana, Patricia Kandus y Priscilla Minotti, entre otros. Todos ellos han participado asesorando a diversas organizaciones de conservación especializadas, tal es el caso de la Fundación Humedales (miembro de la red Wetlands International), como también a organismos del Estado.

Al tiempo que los conocimientos alcanzados por las ciencias naturales fueron sumamente valorados por parte de grupos ambientalistas en cuanto discursos que revirtieron las valoraciones negativas existentes, también esos saberes permitieron la cuantificación de los bienes y servicios de los humedales, allanando el camino hacia su valorización económica como nuevos nichos de realización del capital sobre bienes comunes (Harvey, 2004; Smith, 2007, Swyngedouw, 2011). No está de más recordar que los humedales conservan altos niveles de biodiversidad por lo que se posicionan entre los más destacados "bancos genéticos" del mundo; recursos sobre los que tienen grandes intereses industriales como las alimenticias o las farmacológicas. Además, al ser considerados eficientes sumideros de gases de efecto invernadero, su mercantilización ha comenzado a vehiculizarse a través de los mercados de bonos carbono; propuesta instalada con el Protocolo de Kyoto y que el propio Acuerdo de París, entre otros, fomentan como una de las principales soluciones tecnocráticas ante la crisis climática, en consonancia con los preceptos de la modernización ecológica. 
Diego Ríos, Sergio Caruso

A partir de la década de 1970, y en especial en los años noventa y durante la primera década del nuevo siglo, se fue gestando otra trama de sentidos que retomó la sensibilidad ambientalista, pero ya en clave inmobiliaria. Así se pusieron en valor algunos de los humedales metropolitanos cuyo grado de deterioro y contaminación no era tan significativo. Este giro en la valoración de las aguas de algunos de esos sitios, en el marco de difusión de la escasez del elemento líquido a nivel global, hizo que se convirtiera en un recurso cada vez más raro. Todo lo cual, condujo a que los desarrolladores inmobiliarios inescrupulosos (junto con las autoridades gubernamentales cuyos controles resultaron más que complacientes) se lanzaran de lleno a la apropiación de grandes porciones de humedales "vacantes" en las periferias del aglomerado y de otras áreas inundables de la RMBA.

El modelo urbanístico a seguir fue el de los paisajes de las Gated Communities de los suburbios de Miami en el Estado sureño de la Florida, Estados Unidos, con amplias casas lujosas, rodeadas de jardines con abundante césped, palmeras y demás plantas ornamentales, próximas a cuerpos de aguas, canales y marinas con embarcaciones imponentes. El primer emprendimiento que logró plasmar en Argentina ese imaginario geográfico de suburbio con verde y agua destinado a los grupos más acomodados amantes de la náutica fue el Boating Club (1970) en la zona del Bajo de San Isidro, el cual sirvió de referente para los primeros proyectos y emprendimientos en los bañados de Tigre: el Complejo Urbano Integral Benavidez (1977), que devino, a finales de los noventa, en la mega UC Nordelta, y el club de campo Boat Center (1978) (Ríos, 2010).

Desde finales de los años noventa, los suplementos Countries de los dos diarios de mayor tirada en el país (Clarín y La Nación) y las revistas especializadas en ese submercado inmobiliario exhibían imágenes que reproducen esos modelos urbanísticos y paisajísticos. Las ideas en torno a una naturaleza cuidada y a una vida verde, junto a las ideas de seguridad, privacidad, armonía social, mejor calidad de vida, etc., se destacan en tanto construcción de sentidos reflejada en los anuncios publicitarios de las UC (Carman, 2011; Girola et al., 2004; Svampa, 2001). En las imágenes publicitarias de los paisajes escenográficos de las UC se combinaban los colores verdes intensos del césped y de la vegetación ornamental implantada, junto a las tonalidades pasteles celestes de los cuerpos de agua y del cielo. Se apostaba, de manera creciente, a la necesidad de consumo de espacios verdes, lo que desplegó una carrera sustentada en un discurso de fuerte carga ideológica (Carlos, 1994). Esas estrategias buscaron producir un imaginario geográfico en el que los grupos más acomodados quedaban enlazados a paisajes y naturalezas estetizadas (ocupando las aguas un papel escenográfico central), al tiempo que ocultaban las consecuencias ambientales adversas que conllevaban esas formas de urbanización sobre ecosistemas frágiles como los humedales.

\section{Activación de conflictos ambientales en humedales urbanos: consecuencias adversas, resistencias de nuevos actores $y$ surgimiento de nuevas valoraciones}

En la urbanización de las áreas inundables ubicadas en la periferia metropolitana, los desarrolladores de las UC implementaron técnicas de movimientos de suelos y de refulados hidráulicos con los que se construyeron los rellenos y terraplenes para que 
las zonas de viviendas y usos múltiples quedaran fuera del alcance de las aguas. Esos suelos fueron obtenidos mayoritariamente de los propios humedales, generando nuevos cuerpos de agua de gran cantidad de hectáreas y de hasta 25 a $30 \mathrm{~m}$ de profundidad, llegando incluso a las aguas del acuífero Puelche, como es el caso del lago central de Nordelta. Así, con el pasar del tiempo, los desarrolladores inmobiliarios, los gobiernos y los funcionarios públicos que los apoyaron terminaron transmutando miles de hectáreas de humedales metropolitanos, ${ }^{14}$ deteriorando sus funciones ecológicas y negando aquello que define y regula a esos ecosistemas: las inundaciones (Ríos, 2010).

Ante la envergadura de las modificaciones de las que fueron objeto los humedales de la RMBA, estos sitios se perfilaron como ámbitos de intensa conflictividad ambiental. Al respecto, Sabatini (1997) sostiene que se trata de conflictos que tienen su origen a partir de la superposición de intereses contrapuestos de los actores locales en relación con las externalidades o impactos ambientales que un proyecto dado pudiera tener. Por ello, resulta relevante conocer las valoraciones y la información o desinformación que disponen los grupos intervinientes sobre dichas externalidades y qué consecuencias suponen para la calidad de vida, el ambiente y las economías locales. En este mismo sentido, Merlinsky (2013) los entiende como focos de oposición y/o disputa de índole político que producen tensiones respecto de las modalidades de apropiación, producción, gestión y distribución de los recursos naturales en una comunidad determinada. A la vez, estos conflictos cuestionan las relaciones de poder que habilitan a que ciertos actores tengan acceso a los humedales, mientras que a otros se les restringe o excluye su utilización. Por tanto, se hace evidente que, si bien el nudo problemático remite a impactos ambientales negativos, simultáneamente recupera otras dimensiones desatendidas como la económica, la social y/o la cultural.

El origen de estos conflictos ambientales radicó en la distribución desigual e injusta de las consecuencias adversas generadas por la forma en que se sucedió la expansión de las UC sobre rellenos, especialmente en la cuenca baja del río Luján y en las islas del Delta del municipio de Tigre (Ríos y Pírez, 2008; Pintos y Narodowski, 2012; Astelarra, 2016; Ríos, 2017), o a partir de la posible concreción de grandes proyectos urbanos, tal es el caso de Nueva Costa del Plata (Aizcorbe et al., 2013) en el bajo ribereño perteneciente a Avellaneda y Quilmes. Esa desigualdad e injusticia se basa en la apropiación de los bienes y servicios ambientales por parte de los grupos mejor posicionados y en la externalización de las consecuencias no deseadas del desarrollo, tales como la alteración de la dinámica hídrica que derivó en mayores y más persistentes inundaciones, el cambio de traza de cursos de agua o su creciente contaminación (Ríos, 2017).

El trastocamiento generalizado en la dinámica y en las funciones hídricas de los humedales del RMBA se tradujo en una mayor cantidad de personas expuestas a inundaciones, cuya peligrosidad resultó amplificada ante las características que adoptan los eventos meteorológicos en el actual contexto de CC. Al respecto, sostienen Barros y Camilloni (2016), que para la región en estudio se registra una mayor frecuencia de precipitaciones extremas originadas por sistemas convectivos de mesoescala. ${ }^{15} \mathrm{Si}$ a

14 Según Pintos (agosto de 2020), sólo en la cuenca del río Luján las UC sobre rellenos urbanizaron más de 10.000 ha.

15 Se trata de frentes y ciclones extratropicales conformados por nimboestratos que presentan actividad eléctrica, generan ráfagas de vientos en superficie y que pueden llegar a tener características destructivas (Barros y Camilloni, 2016). 
Humedales, riesgo de desastres y cambio climático...

esto se le suma la incidencia de las sudestadas y el ascenso del nivel medio del mar "se aprecia cómo aumenta el área con riesgo de inundación y (...) [su] recurrencia (...) en áreas que actualmente presentan ese riesgo, incluso el Gran Buenos Aires” (Barros y Camilloni, 2016:250). Por ejemplo, los estragos de las inundaciones catastróficas sucedidas en las ciudades de La Plata y Luján en 2013 y 2015 respectivamente, ${ }^{16}$ fueron resultantes de la conjugación de sistemas convectivos de mesoescala extraordinarios con intervenciones urbanas indebidas e ilícitas, las que menguaron los servicios de amortiguación brindados por los humedales presentes en esos territorios.

En rigor, la emergencia de escenarios altamente contenciosos ha sido plausible dada la desconsideración y el avasallamiento por parte de quienes desarrollan las obras de las UC respecto de la integralidad y condiciones de fragilidad de los humedales. Pero, además, en virtud de los conocimientos de los habitantes que viven del aprovechamiento de sus recursos, quienes han construido un profundo sentido de lugar dependiente de las fluctuaciones del agua características de estos ambientes, y que apelan a valoraciones culturales, recreativas, intrínsecas, religiosas, etc. por sobre otras de índole economicista.

Los conocimientos científico-técnicos elaborados por los ecólogos (entre otras disciplinas de las ciencias naturales) en torno a las funciones ecológicas de los humedales, sumado al compendio de estudios geográficos, urbanísticos, sociológicos, antropológicos, etc., por parte de las ciencias sociales (Ríos, 2002; Fernández, 2002; Ríos y Pírez, 2008; Pintos y Narodowski, 2012; Astelarra, 2016; Schmidt, 2018; Caruso, 2021), resultaron sumamente valiosos para las organizaciones de base, ONG y abogados ambientalistas. Esos conocimientos fueron de gran utilidad en las argumentaciones para elaborar estrategias de resistencia y judicialización de los conflictos ambientales, tales como participaciones en audiencias públicas, denuncias judiciales, manifestaciones, caravanas náuticas, entre otras modalidades de acción. No puede dejar de mencionarse la activa participación y compromiso adoptados por investigadores anfibios, al decir de Maristella Svampa (2008), que articularon su saber experto con su hacer militante. Tales son los casos de Patricia Pintos para la cuenca del río Luján, Sofía Astelarra o Fabio Kalesnik para la zona de islas del Delta, ${ }^{17}$ solo por mencionar algunos.

\section{Los humedales como objeto de políticas públicas: entre la conservación y la reducción del riesgo de desastres ante el cambio climático}

En Argentina, la conservación de la naturaleza mediante las AP se viene desarrollando de manera continua, desde hace poco menos de un siglo al crear sus primeros parques nacionales en 1934. El despliegue de esta política pública, tradicionalmente, se caracterizó por tomar los aportes de los enfoques teóricos que se fueron sucediendo

16 En el caso de La Plata, precipitaron $400 \mathrm{~mm}$ de agua en cuatro horas mientras que, en Luján, Ilovieron 240 $\mathrm{mm}$ en 48 horas (Barros y Camilloni, 2016; Cerrudo, 2017).

17 Algunos de ellos integran el Observatorio de Humedales del Delta, conformado luego de los atropellos realizados por los desarrolladores del proyecto de la UC Colony Park sobre un sector frontal de islas del Delta, que terminaron siendo frenados tanto administrativamente como judicialmente ante las iniciativas de un conjunto de actores locales: "junqueros", ONG y abogados ambientalistas y grupos de investigación universitarios. 
Diego Ríos, Sergio Caruso

en el campo de la ecología (Caruso, 2015). Más recientemente se incorporaron en la gestión los lineamientos derivados de las iniciativas internacionales. Aquí se inscribió el interés por la conservación de los humedales en el país, al adherir a la Convención Ramsar el 4 de septiembre de 1992 tras reglamentarse la Ley Nacional No23.919/91, declarándose a tres AP prexistentes como sus primeros sitios Ramsar. De este modo, algunos frentes fluviales y bajos inundables, que tradicionalmente no habían sido considerados en términos ecológicos, comenzaron a ser valorados como ambientes a ser conservados, tal fue el caso de los parques nacionales Predelta, Ente Ríos (1992) e Islas de Santa Fe, Santa Fe (2010).

Este antecedente, permitió aunar sinergias entre los aportes científicos que se venían desarrollando en la FCNyE-UBA y en el 3iA-UNSAM, y las capacidades de gestión y subvención de la autoridad de aplicación nacional en materia ambiental. En 2017, como resultado de esta alianza y en virtud del financiamiento de Wetland International inscripto en el proyecto El Inventario de los Humedales de Argentina: Una Herramienta para la Implementación de la Convención de Ramsar, el Ministerio de Ambiente y Desarrollo Sustentable publicó la obra Regiones de Humedales de la Argentina. Su finalidad, además de generar información a nivel nacional en un área de vacancia con miras al desarrollo de políticas ambientales, también radicaba en permitir que el país avanzara con los compromisos asumidos ante "las Metas de Sendai para la Reducción del Riesgo de Desastres y el objetivo del Acuerdo de París sobre el cambio climático" (Benzaquén et al., 2017:8). De este modo, se pudo dar a conocer que los humedales de Argentina ocupaban aproximadamente una superficie de $600.000 \mathrm{~km}^{2}$, representando el 21,5\% del territorio nacional (Kandus et al., 2008). Este criterio ecológico supone entenderlos como ámbitos física y funcionalmente delimitables, aislados de las tramas de intereses y relaciones de poder en las que se inscriben. No obstante, tal como plantean Straccia et al. (2021), la afectación de los intereses de los capitales inmobiliarios, mineros y forestales fue uno de los principales mecanismos que obturaron toda posibilidad de protección formal de estos ambientes, como se verá a continuación.

Los incendios de pastizales del Delta del Paraná durante el 2008, cuyos impactos se percibieron en la RMBA y en Rosario, pusieron en la agenda pública las formas inadecuadas de uso y aprovechamiento de esos humedales. En un contexto de creciente interés social por dichos ambientes, y dada la capacidad de tracción y de articulación de las principales ONG conservacionistas del país con los legisladores nacionales, en 2013 se presentaron en el Congreso de la Nación dos iniciativas que se fusionaron en una: el Proyecto de Ley de Presupuestos Mínimos para la Conservación, Protección, Restauración Ecológica y Uso Racional y Sostenible de los Humedales (conocida como la Ley de Humedales), conforme el Artículo $\mathrm{N}^{\circ} 41$ de la Constitución Nacional (Straccia e Isla Rafaelle, 2020). Si bien la medida obtuvo media sanción en el Senado, fue rechaza por la Cámara de Diputados dadas las presiones de los sectores de los negocios inmobiliarios y el minero, perdiendo el estado parlamentario a fines de 2015. Luego, entre 2016 y 2019 se presentaron otras cinco iniciativas que tampoco lograron tomar estado parlamentario. ${ }^{18}$

Más adelante, otro ciclo de incendios intencionales sobre humedales adyacentes al río Paraná registrados durante el 2020 produjeron importantes estragos ambientales

18 Para ahondar en estas iniciativas véase el sitio: https://www.leydehumedalesya.org/ 
Diego Ríos, Sergio Caruso

y sociales. Los fuegos afectaron las tierras de los parques nacionales Islas de Santa Fe y Predelta. La dispersión de las humaredas resultantes alcanzaron a la ciudad de Rosario y a otras localidades aledañas. Ante este panorama, se posicionó en el primer plano de la agenda pública nacional la urgencia de disponer de una ley para este tipo de ambientes, presentándose quince proyectos en ese mismo año. Ratificándose, una vez más, tal como señalan Astelarra et al. (2017), la alta conflictividad que caracterizan a estos ambientes.

En sintonía con la relevancia que los humedales fueron tomando en el plano nacional, la provincia de Buenos Aires los incorporó como materia de política ambiental poco tiempo después. Su origen estuvo vinculado a las presiones que implicó la construcción de las UC sobre el Delta del Paraná y la cuenca del río Luján (Mulvany et al., 2019). Justamente, las inundaciones catastróficas ocurridas en esa localidad durante el 2015 y asociadas a los sistemas convectivos de mesoescala, aceleraron la producción del Inventario de Humedales de la Provincia de Buenos Aires (Mulvany y Canciani, 2019) a nivel de sistema de paisajes de humedales, congruente metodológicamente con el Inventario Nacional de Humedales. Además, habilitaron la presentación de un proyecto de "ley de humedales" en la Cámara de Diputados provincial que aún espera tratamiento en diversas comisiones para ingresar al recinto.

Entretanto, la RMBA no estuvo exenta de este proceso y desde finales de los años ochenta en adelante se establecieron a lo largo de su territorio AP de jurisdicción municipal y provincial que tenían por objeto conservar los relictos de sus humedales. Sin embargo, sólo unas pocas lograron consolidarse como tales, ${ }^{19}$ dado el desinterés por parte de las autoridades municipales y provinciales. Esto respondió a que dichos sitios no fueron planificados por la relevancia de sus valores naturales, sino como espacios remanentes que no llegaron a ser alcanzados por la expansión urbana de la RMBA (Chebez et al., 2012). En la actualidad, la desidia por parte de las autoridades de aplicación que instaura las llamadas "reservas de papel" es un foco de emergencia de la conflictividad ambiental, tal como se ha observado en el caso de las reservas Santa Catalina (Schmidt, 2018), Ciudad Evita (Wertheimer y Pereira, 2020) y Laguna de Rocha (Schmidt, 2016; y Caruso y Ríos, 2021), entre otras.

En línea con su política de difusión sobre la conservación de los humedales en ámbitos citadinos, la Convención Ramsar publicó en 2012 los Principios para la Planificación y el Manejo de los Humedales Urbanos y Periurbanos. Este documento estableció las bases para que, a partir de 2015, las urbes con jurisdicción de gobierno ${ }^{20}$ pudieran acreditarse como Ciudad de Humedal. De esta manera, y en el contexto del CC, Ramsar destacó la capacidad de adaptación y mitigación al calentamiento global de estos ambientes tanto por funcionar como sumidero de gases de efecto invernadero, así como por amortiguar los impactos de las tormentas y de las inundaciones (Ramsar, 2012). En cuanto a la RRD, en el documento Humedales para la Reducción de Riesgo de Desastre, se destacaron sus funciones como barreras protectoras de las líneas costeras y su capacidad de almacenaje y de absorción de los excesos de agua provenientes de los eventos meteorológicos (Ramsar, 2017a).

19 La Reserva Natural Municipal Ribera Norte en San Isidro es uno de los ejemplos más emblemáticos.

20 Refiere a una ciudad que tenga su propio sistema de gobierno, es decir, una autoridad o autoridades municipales (Ramsar, 2015) 
Diego Ríos, Sergio Caruso

Con el objetivo de alcanzar los estándares de las ciudades sustentables, los relictos de humedales bajo la figura de AP y otros espacios verdes (parques, plazas, corredores, etc.) comenzaron a ser ponderados en materia de sustentabilidad ambiental, ante la posibilidad de articularlos mediante corredores biológicos a escala metropolitana. ${ }^{21}$ Este interés fue activado por el lado de los especialistas de la conservación, quienes veían no sólo la posibilidad de consolidar sus procesos ecosistémicos, la migración y la salvaguarda de especies, sino también de asegurar sus funciones de esparcimiento y educación ambiental (Bertonatti, 2015). Pero además estas iniciativas fueron impulsadas desde el plano de la planificación y ordenamiento urbano-ambiental, en donde la recuperación de los humedales se ubicó entre las políticas públicas más dinámicas, teniendo por objeto la preservación de la llamada biodiversidad urbana (Garay y Fernández, 2013). Un denominador común en el que convergieron ambas propuestas remitió a los servicios ambientales que estos sitios le provén a la RMBA, no sólo en la mejora de la calidad del aire y del agua o como reservorio de biodiversidad, sino especialmente aquellos vinculados con la adaptación y mitigación de la peligrosidad de los eventos hidrometeorológicos extremos en el contexto del CC. Así, estos aspectos estuvieron presentes en la declaratoria de la Reserva Ecológica Costanera Sur como Sitio Ramsar (Ramsar, 2005). Además, la reciente posibilidad de obtener la categoría Ciudad de Humedal, podría ser entendida como una instancia tendiente a reforzar la valoración, jerarquización y multiplicación de las AP en la RMBA.

Por último, debe destacarse la convalidación de los humedales artificiales, tales como estanques, reservorios, diques, etc., en el sistema de clasificación de la Convención Ramsar, entendidos como medidas compensatorias válidas ante el rápido avance de la urbanización y sus implicancias en el marco del CC (Ramsar, 2017b). La proliferación de este tipo de iniciativas en la RMBA avanza en esa dirección. Uno de los casos más emblemáticos es el de San Isidro, municipio que viene desarrollando una red de reservorios artificiales en distintas zonas de su territorio, como estrategia adaptativa ante los eventos hidrometeorológicos extremos. Así, este distrito que siempre quiso diferenciarse (San Isidro es distinto expresa su propuesta publicitaria) busca posicionarse como un municipio de vanguardia en el marco de las propuestas de la modernización ecológica vinculadas con la RRD ante el CC. Además, la lógica de esta iniciativa revestiría potencial para resignificar, revalorizar e impulsar ciertas obras hidráulicas ya proyectadas empero aún no realizadas, como por ejemplo los once reservorios de agua que la Autoridad de Cuenca Matanza-Riachuelo (ACUMAR) plantea construir a lo largo de la cuenca media y alta Matanza-Riachuelo (ACUMAR, s/f). Al almacenar los excesos hídricos activados por precipitaciones, esos reservorios permitirían controlar los picos de caudal del río Matanza, mitigar los efectos de las inundaciones aguas abajo y funcionar como ambiente de humedal.

\section{Consideraciones finales}

El reposicionamiento de los humedales de la RMBA acontecido a partir de las últimas décadas encuentra sus cimientos en la mayor frecuencia e intensidad de los eventos

21 Ejemplo de ello son las propuestas de articulación de los parques lineales a lo largo del frente fluvial del Río de La Plata en los municipios de la zona Norte de la RMBA; o bien, la generación de un corredor biológico en la cuenca media Matanza-Riachuelo que asegure el flujo de los procesos ecosistémicos entre las distintas lagunas que allí se localizan. 
hidrometeorológicos extremos atribuidos al CC, en el intenso trastrocamiento del que fueron objeto esos ambientes por parte de la expansión de las UC sobre rellenos destinados a los grupos más beneficiados, y en el aumento de su ocupación protagonizada por comunidades cada vez más marginalizadas y vulnerabilizadas a causa de las políticas neoliberales preponderantes, entre otros motivos.

En un contexto de creciente difusión de la sensibilidad ambientalista, de evidencias sobre las inundaciones catastróficas, del conocimiento acerca de los servicios ambientales que los humedales proveen a las ciudades y sociedades, y de medidas de mitigación y adaptación según los parámetros de la RRD ante el CC, se advierte una reinversión de las tramas de sentidos respecto de los imaginarios geográficos construidos en torno a las áreas inundables. Muchas de las "tierras de agua" de la RMBA, consideradas mayormente como inservibles, insalubres, degradadas, marginales o peligrosas, pasaron a posicionarse como humedales cuyos bienes y servicios ambientales están siendo valorados y defendidos por un conjunto de actores sociales diversos.

Conforme convergían distintas valoraciones que implicaban la concreción de determinadas acciones e intereses, generalmente incompatibles entre sí, los humedales urbanos comenzaron a establecerse como ámbitos de marcada conflictividad ambiental. El enrolamiento detrás de la protección de las funciones, los recursos y los servicios de estos ambientes permitió la confluencia de los conocimientos de académicos, activistas y comunidades locales para asegurar el control de esos territorios, los usos sociales, culturales y económicos que los lugareños venían desarrollando en ellos y litigar en el campo contencioso. Esto explica que cada vez sea más habitual la juridificación de los conflictos ambientales (Merlinsky, 2010). Así, las cortes y los tribunales se establecen como ámbitos legitimados socialmente en donde dirimir dichas controversias. En función de algunos fallos recientes, ${ }^{22}$ pareciera ser auspicioso el entendimiento que la Administración de Justicia realiza respeto a los servicios ambientales y las funciones sociales de los humedales de la RMBA. Todo lo cual, dialoga con la ocurrencia de estragos cada vez más dolosos en los que se relacionan los eventos hidrometeorológicos extremos y las responsabilidades de aquellos que urbanizan indebida e ilegalmente a esos ecosistemas estratégicos.

Desde el plano de la gestión, el tema ingresó como materia de política ambiental hace unas pocas décadas tanto a nivel nacional como metropolitano, impulsado por la agenda de los organismos internacionales (Ramsar, Metas de Sendai, Acuerdo de París, etc.), así como por el interés social y la importante conflictividad que caracterizó a los humedales de la RMBA. Si bien estos ambientes están siendo lentamente inventariados y preservados mediante las declaratorias de AP, salvo algunas pocas excepciones, ha primado la desidia de las autoridades de aplicación municipales y provincial. Esto, además de responder a la falta de recursos para gestionarlas, se arraigó en una tradición conservacionista apuntalada en la protección de sitios lo "más prístinos posibles", que aún se resiste a incorporar en su acervo reservas urbanas emplazadas en una compleja trama urbana, cuyos manejos requieren de instancias de abordaje social y territorial. 
Sin embargo, las jurisdicciones también entienden que contar con humedales bajo la figura de AP, homologadas con los estándares de las iniciativas internacionales (como los sitios Ramsar), habilita la posibilidad de obtener financiamiento externo para gestionarlas. Asimismo, los argumentos a favor de los humedales implementados por las autoridades gubernamentales y otros actores, están resultando muchas veces en un instrumento útil para justificar las expulsiones coercitivas o las relocalizaciones "consensuadas" de los grupos más marginalizados y vulnerables que habitaban tradicionalmente esos sitios, a los que se ha tratado de insustentables, tal como se evidenció en varias investigaciones realizadas en reservas urbanas (Carman, 2011; Wertheimer y Pereira, 2020; Caruso, 2021, entre otros). Todo lo cual plantea los siguientes interrogantes respecto de esos grupos: qué lugar ocupan en los conflictos; cómo intervienen -si es que lo hacen- en el diseño de las políticas ambientales, y cuáles alternativas se les brinda para habitar la ciudad luego de que las áreas inundables reciben protección legal mediante las figuras de AP.

Los humedales se están volviendo cada vez más prioritarios entre las políticas públicas ambientales de los gobiernos a fin de posicionar sus jurisdicciones en el listado de las llamadas ciudades sostenibles o en el de la nueva categorización de ciudad de humedal de Ramsar. Desde los postulados de la modernización ecológica, los humedales se han convertido en infraestructuras verdes y azules que, utilizadas como soluciones basadas en la naturaleza, adquieren gran valoración para los fines de mitigación y adaptación según las propuestas de RRD ante el CC. Si bien en la RMBA estas líneas aún no se han desplegado en profundidad, es dable inferir que en el corto y mediano plazo lo hagan, siguiendo lo que acontece con este tema en las ciudades de los países centrales.

Finalmente, ante la profunda situación de crisis urbano-ambiental que nos presenta el desbarajuste climático y, desde 2020, epidemiológico en el que estamos navegando con dirección incierta, el capital y demás actores que defienden sus intereses proponen soluciones tecnocráticas. Las respuestas ya no sólo se reducen al compendio de las nuevas ecoingenierías, sino que se va un paso más allá al concebir a determinados ecosistemas junto a las amplias extensiones territoriales que ocupan, como "máquinas híbridas eficientes" que brindan servicios ambientales mercantilizables, como es el caso de los humedales. El capital, mediante esta operación que implica un cambio de escala, abre el camino hacia nuevas formas y fronteras de mercantilización de las condiciones naturales. De este modo, expolia los bienes comunes que habían quedado más rezagados en términos relativos y que se convirtieron en objeto de una acumulación por desposesión totalmente desenfrenada. Se deja fuera de la discusión la posibilidad de que otras formas de organización social (superadoras del capitalismo actual) no solo viabilicen una vida más digna, vivible y menos vulnerable para las mayorías, sino que además se obtura la posibilidad de vinculaciones más respetuosas con aquello que llaman de naturaleza, tanto en su condición de normalidad como en sus manifestaciones extremas. 


\section{Q Bibliografía}

» ACUMAR (s/f). Autopista Presidente Perón tramos I, II y III. Zonas de extracción de suelos para la obra y modificación parcial del Plan Director Básico de Drenaje Pluvial de la Cuenca Matanza Riachuelo. Ciudad Autónoma de Buenos Aires: ACUMAR. Recuperado de: https://www.acumar.gob.ar/wp-content/ uploads/2016/12/documentos_hidricos_1.pdf

» Aizcorbe, M., Fernández Bouzo, S. y Wertheimer, M. (2013). "Moros en la costa”. Ambiente, actores locales y conflicto en torno a megaproyectos de urbanización sobre la franja costera de los partidos de Avellaneda, Quilmes y Vicente López (2000-2011). En G. Merlinsky (Comp.), Cartografías del conflicto ambiental en Argentina (pp. 173-200). Buenos Aires: CICCUS.

»Astelarra, S. (2016). Disputas por la reinvención del "paraíso deltaico": de los lugares de la querencia a llegar a una isla y olvidarse de todo. El caso del conflicto "Colony Park" en la primera sección de islas del Delta del Paraná. En G. Merlinsky (Comp.), Cartografías del conflicto ambiental en Argentina 2 (pp. 81-110). Buenos Aires: CICCUS.

» Astelarra, S., de la Cal, V. y Domínguez, D. (2017). Conflictos en los Sitios Ramsar de Argentina: aportes para una ecología política de los humedales. Letras Verdes, 22, 228-247.

» Barros, V. y Camilloni, I. (2016). La Argentina y el cambio climático. De la física a la política. Buenos Aires: Eudeba.

» Benzaquén, L., Blanco, D., Bo, R., Kandus, P., Lingua, G., Minotti, P. y Quintana, R. (Eds.) (2017). Regiones de humedales de la Argentina. Buenos Aires: Ministerio de Ambiente y Desarrollo Sustentable.

» Bertonatti, C. (2015). La estructura ecológica de las ciudades y su importancia cultural y ambiental. En A. Di Pangracio, A. Napoli y F. Sangalli (Eds.), Informe Ambiental Anual 2015 (pp. 273-282). Buenos Aires: Fundación Ambiente y Recursos Naturales.

» Calderón, G. (2001). Construcción y reconstrucción del desastre. Ciudad de México: Plaza y Valdés.

»Carlos, A.F. (1994). O meio ambiente urbano e o discurso ecológico. Revista do Departamento de Geografia, 8, 75-78.

» Carson, R. (2016). Primavera Silenciosa. Madrid: Edición Crítica. (Publicación original 1962).

» Carman, M. (2011). Las trampas de la naturaleza: medio ambiente y segregación en Buenos Aires. Buenos Aires: Fondo de Cultura Económica, CLACSO.

»Caruso, S. (2015). Análisis del Proceso de Creación de Áreas Naturales Protegidas por Parte de la Administración de Parques Nacionales en Argentina 1934-2015. Cardinalis, 3(5), 132-160.

» Caruso, S. (2021). Riesgo, conflicto, políticas de relocalización y conservación ambiental en una zona inundable en disputa en la periferia Sur del Gran Buenos Aires: los casos del asentamiento 9 de Enero y de la Laguna de Rocha, localidad de 9 de Abril, Esteban Echeverría. Tesis de Maestría en Políticas Ambientales y 
Diego Ríos, Sergio Caruso

Territoriales, Facultad de Filosofía y Letras, Universidad de Buenos Aires.

» Caruso, S. y Ríos, D. (2021). Urbanización, conservación de humedales y conflictos ambientales: el caso de la Laguna de Rocha. Boletín de Estudios Geográficos, 114, 77-100.

»Cerrudo, C. (2017). El todo es más que la suma de las partes. Meteoros, 9(4), 15-21.

»Chebez, J., Gasparri, B. y Athor, J. (2012). Las reservas y espacios verdes urbanos. Historia y actualidad. En J. Athor (Ed.), Buenos Aires. La historia de su paisaje natural (pp. 390-409). Ciudad Autónoma de Buenos Aires: Fundación de Historia Natural Félix de Azara.

" Collins, T. (2010). Marginalization, Facilitation, and the Production of Unequal Risk: The 2006 Paso del Norte Floods. Antipode, 42(2), 258-288.

» Cravino, M., Del Río, J. y Duarte, J. (2008). Un acercamiento a la dimensión cuantitativa de los asentamientos y villas del Área Metropolitana de Buenos Aires. En C. Cravino (Org.), Los mil barrios (in)formales. Aportes para la construcción de un observatorio del hábitat popular del Área Metropolitana de Buenos Aires (pp. 87-152). Los Polvorines: Universidad Nacional de General Sarmiento.

»De Souza Porto, M. (2007). Uma ecologia política dos riscos. Princípios para integrarmos o local e o global na promoção da saúde e da justiça ambiental. Rio de Janeiro: Editora FIOCRUZ.

" Fernández, L. (2002). Los servicios ecológicos que cumplen los humedales, el caso de Tigre, Buenos Aires. Tesis de licenciatura en Ecología Urbana, Universidad Nacional de General Sarmiento.

》 Garay, D. y Fernández, L. (2013). Biodiversidad urbana. Apuntes para un sistema de áreas verdes en la región metropolitana de Buenos Aires. Los Polvorines: Universidad Nacional de General Sarmiento.

》 Girola, M.F., Lacarrieu, M. y Murgida, A.M. (2004). Usos de la naturaleza y experiencias de lo barrial en urbanizaciones cerradas del Gran Buenos Aires. Etnia, 46-47,169-186.

»González, S. (2018). Riesgo hídrico y planificación urbana en la ciudad de Buenos Aires. Estudios del Hábitat, 16(2), 1-13.

》González, S y Ríos, D. (2015). Producción desigual de espacios de riesgo de desastres y transformaciones urbanas recientes en áreas inundables de Buenos Aires: los casos de Palermo y Tigre. En C. Natenzon y D. Ríos (Eds.), Riesgos, catástrofes y vulnerabilidades. Aportes desde la Geografía y otras ciencias sociales para casos argentinos (pp. 139-163). Buenos Aires: Imago Mundi.

» Harvey, D. (2004). The "New" Imperialism: Accumulation by Dispossession. Socialist Register, 40, 63-87.

»Hiernaux, D. y Lindón, A. (2007). Imaginarios urbanos desde América Latina: tradiciones y nuevas perspectivas. En A. Silva (Eds.), Imaginarios urbanos en América Latina: Archivos (pp. 157-167). Barcelona: Fundación Antoni Tapies.

» Kalesnik, F. y Quintana, R. (2006). El delta del río Paraná como un mosaico de humedales. Caso de estudio: la Reserva de biosfera MAB-UNESCO "Delta Del Paraná". Geociências, 5(1), 22-37.

》 Kandus, P y Minotti, P. (2018). Propuesta de un marco conceptual y lineamientos metodológicos para el Inventario Nacional de Humedales. Buenos Aires: Instituto de Investigación e Ingeniería Ambiental, Universidad Nacional de San Martín. 
Diego Ríos, Sergio Caruso

» Kandus, P., Quintana, R. y Malvárez, M. (2008) Distribution of wetlands in Argentina estimated from soil charts. Acta Scientiarum Biological Sciences, 30(4), 403-409.

» Mansilla, E. (2000). Riesgo y ciudad. Ciudad de México: Universidad Autónoma de México, División de Estudios de Posgrado, Facultad de Arquitectura.

»Merlinsky, G. (2010). La juridificación de los conflictos ambientales en Argentina: actores, controversias y construcción de derechos. XXIX Congreso Internacional de la Asociación de Estudios Latinoamericanos (LASA, 2010). Toronto, Canadá.

» Merlinsky, G. (2013). Cartografías del conflicto ambiental en Argentina. Buenos Aires: CICCUS

»Evaluación de los Ecosistemas del Milenio (2005). Los ecosistemas y el bienestar humano: humedales y agua. Informe de síntesis. Washington, D.C.: World Resources Institute. Recuperado de: https://www.millenniumassessment.org/ documents/MA_WetlandsandWater_Spanish.pdf

» Mitsch, W. y Gosselink, J. (1993). Wetlands. Nueva York: Van Nostrand Reinhold. (Publicación original: 1986).

» Mulvany, S.H. y Canciani, M.H. (Coord.) (2019). Inventario de Humedales de la Provincia de Buenos Aires. Nivel 2: Sistemas de Paisajes de Humedales. Primer informe. La Plata: Gobierno de la Provincia de Buenos Aires, OPDS.

» Mulvany, S., Canciani, M.H.,Pérez Safontas, M.,Sánchez Actis, T.,Tangorra, M. y Sahade, E. (2019). Inventario de humedales de la provincia de Buenos Aires. Nivel 2. Sistemas de Paisajes de Humedales: principales aspectos operativos y metodológicos. XXI Jornadas de Geografía de la UNLP. La Plata, Argentina.

»Oltra, C. (2005). Modernización Ecológica y sociedad del riesgo. Hacia un análisis de las relaciones entre ciencia, medio ambiente y sociedad. Papers, Revista de Sociología, 78, 133-149.

»Pereyra, F. (2002). Evolución geológica de la región. En J. M Borthagaray (Comp.), El Río de la Plata como territorio (pp.15-50). Buenos Aires: Infinito.

»Pintos, P. (2020, agosto). Sobre la ocupación de humedales. Bienes comunes de la naturaleza cuya existencia es determinante para las sociedades que los poseen. Café de las ciudades. Recuperado de: https://cafedelasciudades.com. ar/sitio/contenidos/ver/350/sobre-la-ocupacion-de-humedales-bienes-comunesde-la-naturaleza-cuya-existencia-es-determinante-para-las-sociedades-que-losposeen.html

»Pintos, P. y Narodowski, P. (Coords.) (2012). La privatopia sacrílega. Efectos del urbanismo privado en humedales de la cuenca baja del río Luján. Buenos Aires: Imago Mundi.

》Ramsar (2005). Ficha Informativa de Los de Ramsar (FIR) Reserva Ecológica Costanera Sur. Recuperado de: https://rsis.ramsar.org/RISapp/files/RISrep/ AR1459RIS.pdf

»Ramsar (2012). Resolución X.11. Principios para la planificación y el manejo de los humedales urbanos y periubranos. Recuperado de: https://www.ramsar.org/sites/ default/files/documents/pdf/cop11/res/cop11-res11-s.pdf

»Ramsar (2015). Resolución XII.10. Acreditación de Ciudad de Humedal de la Convención de Ramsar. Recuperado de: https://www.ramsar.org/sites/default/ files/documents/library/cop12_res10_wetland_cities_s_0.pdf 
»Ramsar (2017a). Humedales para la reducción de riesgo de desastres: Opciones eficaces para comunidades resilientes. Recuperado de: https://www.ramsar.org/ sites/default/files/documents/library/rpb_wetlands_and_drr_s.pdf

»Ramsar (2017b). Notas de orientaciones para ciudades sobre la acreditación de Ciudad de Humedal. Recuperado de: https://www.ramsar.org/sites/default/files/ documents/library/wca_guidance_for_cities_s.pdf

»Ríos, D. (2002). Vulnerabilidad, urbanizaciones cerradas e inundaciones en el partido de Tigre, durante el período 1990-2001. Tesis de licenciatura en Geografía, Facultad de Filosofía y Letras, Universidad de Buenos Aires.

"Ríos, D. (2010). Producción de espacio de riesgo de desastres a partir de la urbanización de áreas inundables. Los bañados de Tigre, su historia y sus transformaciones recientes. Tesis de doctorado en Geografía, Facultad de Filosofía y Letras, Universidad de Buenos Aires.

》Ríos, D. (2017). Aguas turbias: los nuevos cuerpos de agua de las urbanizaciones cerradas de Buenos Aires. Cuadernos de Geografía: Revista Colombiana de Geografía, 26(1), 201-219.

» Ríos, D. y Pírez P. (2008). Urbanizaciones cerradas en áreas inundables del municipio de Tigre: ¿producción de espacio urbano de alta calidad ambiental? Eure, 34(101), 99-119.

》 Ríos, D. y Natenzon, C. (2015). Una revisión sobre catástrofes, riesgo y ciencias sociales. En C. Natenzon y D. Ríos (Eds.), Riesgos, catástrofes y vulnerabilidades. Aportes desde la Geografía y otras ciencias sociales para casos argentinos (pp. 1-27). Buenos Aires: Imago Mundi.

"Sabatini, F. (1997). Conflictos ambientales y desarrollo sustentable de las regiones urbanas. EURE, 22(68), 77-91.

"Schmidt, M. (2016). "De las joyas que tiene el Riachuelo, es una de las más lindas". Política ambiental y ordenamiento del territorio en la cuenca MatanzaRiachuelo, el caso de la Laguna de Rocha. En G. Merlinsky (Comp.), Cartografías del conflicto ambiental en Argentina II (pp. 315-349). Buenos Aires: CICCUS.

》Schmidt, M. (2018). Conflictos por la valoración de humedales en ámbitos urbanos. La cuenca Matanza Riachuelo, Argentina. Bitácora Urbano Territorial, 28(3), 89-118.

» Silvestri, G. (2003). El color del río. Historia cultural del paisaje del Riachuelo. Buenos Aires: Editorial de la Universidad Nacional de Quilmes, Prometeo.

»Smith, N. (2007). Nature as accumulation strategy. Socialist Register, 43, 1-21.

》 Straccia, P. e Isla Raffaelle, M.L. (2020). Leyes de presupuestos mínimos de protección ambiental. Sobre glaciares, humedales y la emergencia del carácter político de categorías despolitizadas. Ecología Austral, 30, 85-98.

"Straccia, P., Monkes, J. e Isla Raffaele, M.L. (2021). Las políticas de escala en las disputas ambientales: el caso de los humedales en Argentina. Huellas, 25(1), 73-91.

»Svampa, M. (2001). Los que ganaron: la vida en los countries y barrios privados. Buenos Aires: Biblos.

»Svampa, M. (2008). Cambio de época. Movimientos sociales y poder político. Buenos Aires: Siglo XXI. 
Humedales, riesgo de desastres y cambio climático...

Diego Ríos, Sergio Caruso

»Swyngedouw, E. (2011). ¡La naturaleza no existe! La sostenibilidad como síntoma de una planificación despolitizada. Revista Urban, 1, 41-66.

»Vileisis, A. (1999). Discovering the Unknown Landscape: A History of America's Wetlands. Washington, DC: Island Press.

"Wertheimer, M. y Pereira, P. (2020). Conservación de ecosistemas "naturales" en el contexto de disputas por acceso al suelo urbano. El caso de la Reserva Natural Ciudad Evita (Buenos Aires, Argentina). Revista Vivienda y Ciudad, 7, 66-87.

"Williams, F. (2017). Los ríos de Buenos Aires: una perspectiva histórica. En M. Charrière (Ed.), Costas y cuencas de la Región Metropolitana de Buenos Aires: estudios, planes y proyectos (pp. 17-23). Buenos Aires: Consejo Profesional de Arquitectura y Urbanismo.

\section{Diego Ríos / diegorios@conicet.gov.ar}

Licenciado en Geografía y Doctor en Filosofía y Letras (con mención en Geografía) por la Universidad de Buenos Aires-UBA. Es investigador Adjunto del CONICET con sede de trabajo en el Instituto de Geografía, UBA, en donde participa del Programa de Investigaciones en Recursos Naturales y Ambiente (PIRNA) y del Grupo Cultura, Naturaleza y Territorio. Docente de grado en la carrera de Geografía-UBA y posgrados. Sus líneas de investigación abordan los procesos de urbanización, la producción de espacios de riesgo de desastres y la configuración de imaginarios geográficos en áreas inundables/humedales.

\section{Sergio Caruso / scaruso@filo.uba.ar}

Licenciado en Geografía y Magíster en Políticas Ambientales y Territoriales por la UBA. Doctorando en Geografía de la UBA y Becario Doctoral del CONICET con sede Instituto de Geografía, UBA, donde participa en el PIRNA. Docente de grado de la carrera de Geografía, UBA. Investiga temáticas relativas a la producción de espacios de riesgo de desastres mediante la urbanización de áreas inundables/humedales, a la conservación de la naturaleza mediante áreas protegidas y a los conflictos ambientales. 